\title{
Dual Effect of Acetic Acid Efficiently Enhances Sludge-Based Biochar to Recover Uranium From Aqueous Solution
}

\section{OPEN ACCESS}

Edited by:

Shuaifei Zhao,

Deakin University, Australia

Reviewed by:

Jin Wang,

Guangzhou University, China

Yanbiao Liu,

Donghua University, China

Min Wang,

Jinan University, China

*Correspondence:

Xiaoyan Wu

wuxiaoyan@usc.edu.cn

Yong Liu

1992001751@usc.edu.cn

Specialty section: This article was submitted to

Inorganic Chemistry,

a section of the journal

Frontiers in Chemistry

Received: 15 December 2021

Accepted: 11 January 2022

Published: 22 February 2022

Citation:

Yu S, Wu X, Ye J, Li M, Zhang Q, Zhang X, Lv C, Xie W, Shi K and Liu Y

(2022) Dual Effect of Acetic Acid Efficiently Enhances Sludge-Based Biochar to Recover Uranium From

Aqueous Solution.

Front. Chem. 10:835959.

doi: 10.3389/fchem.2022.835959
Shoufu $Y u^{1}$, Xiaoyan $W u^{1,2,3 *}$, Jian $Y e^{1,2,3}, M i i^{1,2,3}$, Qiucai Zhang ${ }^{1,4}$, Xiaowen Zhang ${ }^{1,2,3}$, Chunxue $\mathrm{Lv}^{1}$, Wenjie Xie ${ }^{1}$, Keyou Shi ${ }^{1}$ and Yong Liu ${ }^{1,4 *}$

${ }^{1}$ University of South China, Hengyang, China, ${ }^{2}$ Hengyang Key Laboratory of Soil Contamination Control and Remediation, University of South China, Hengyang, China, ${ }^{3}$ Key Laboratory of Radioactive Waste Treatment and Disposal, University of South China, Hengyang, China, ${ }^{4}$ Decommissioning Engineering Technology Research Center of Hunan Province Uranium Tailings Reservoir, University of South China, Hengyang, China

Excess sludge (ES) treatment and that related to the uranium recovery from uraniumcontaining wastewater (UCW) are two hot topics in the field of environmental engineering. Sludge-based biochar (SBB) prepared from ES was used to recover uranium from UCW. Excellent effects were achieved when SBB was modified by acetic acid. Compared with SBB, acetic acid-modified SBB (ASBB) has shown three characteristics deserving interest: 1) high sorption efficiency, in which the sorption ratio of $U(\mathrm{VI})$ was increased by as high as 35.0\%; 2) fast sorption rate, as the equilibrium could be achieved within 5.0 min; 3) satisfied sorption/desorption behavior; as a matter of fact, the sorption rate of $\mathrm{U}(\mathrm{VI})$ could still be maintained at $93.0 \%$ during the test cycles. In addition, based on the test conditions and various characterization results, it emerged as a dual effect of acetic acid on the surface of SBB, i.e., to increase the porosity and add $(-\mathrm{COOH})$ groups. It was revealed that $\mathrm{U}(\mathrm{VI})$ and -COO- combined in the surface aperture of ASBB via single-dentate coordination. Altogether, a new utilization mode for SBB is here proposed, as a means of efficient uranium sorption from UCW.

Keywords: uranium, uranium-containing wastewater, excess sludge, acetic acid, sludge-based biochar

\section{INTRODUCTION}

Uranium-containing wastewater (UCW) contains a certain concentration of nuclide ions, such as uranium ions, radium ions, and thorium ions. In addition, it also contains high concentrations of heavy metal ions, metal ions, and acid ions, such as sulfate ions and nitrate ions. This special industrial wastewater is mainly discharged by uranium mining or uranium hydrometallurgy. Generally, uranium presents in the valence form of U(IV) and U(VI). U(IV) does not dissolve in aqueous solution and usually forms precipitation, while $\mathrm{U}(\mathrm{VI})$ generally gives mobile aqueous

Abbreviations: ASBB, acid-modified sludge-based biochar; ASBB-U, Acetic acid-modified sludge-based biochar-uranium; BET, Brunner-Emmet-Teller; EDS, energy-dispersive x-ray spectroscopy; ES, excess sludge; FTIR, Fourier transform infrared spectroscopy; SBB, sludge-based biochar; SEM, scanning electron microscope; SSA, specific surface area; UCW, uraniumcontaining wastewater; WWTP, wastewater treatment plant; XPS, x-ray photoelectron spectroscopy. 
complexes with $\mathrm{CO}_{3}{ }^{2-}$ and $\mathrm{OH}^{-1}$ (Gerber et al., 2016; Abdi et al., 2017). Uranium ions are characterized by radioactivity and chemical toxicity, which could, in turn, cause chronic poisoning, cancer, and immunological diseases (Malenchenko et al., 1978; Baur et al., 1996; Kathren and Burklin, 2008; NaserHumood, 2013). In addition, serious damage might be caused to the surrounding organisms as well as ecosystems once UCW is discharged into the environment by accident. Consequently, it is of great significance to establish rapid and efficient processing methods for UCW treatment aimed at both reducing the hazardous effect of UCW and reusing, as addedvalue product, uranium recovered by UCW.

At present, the main technologies for uranium recovered from UCW or UCW treatment could be summarized as chemical precipitation, ion exchange, membrane separation, biological treatment, solvent extraction, and sorption (Khani et al., 2008; Wang et al., 2009; Abadi et al., 2011; Gerber et al., 2016; Khawassek et al., 2018; Tan et al., 2018). Among them, sorption is one of the popular technologies because of its advantages, including simple operation, wide range of application, higher removal and recovery rate, etc. (Chen et al., 2020). Generally, the uranium removal rate by sorption is mainly influenced by physical/chemical properties of adsorbents (i.e., pore structure, surface groups), uranium concentration, pH, etc. (Kataria and Garg, 2018) Biochar (Sun et al., 2013; Sun et al., 2017; Kong et al., 2020), graphene (Zhao et al., 2019), calixarene (Fang-Zhu et al., 2019), MOFs (Li et al., 2020), and mesoporous silicon (Jiang et al., 2020) were used as sorption materials. Among them, biochar has been verified as an important sorption material for uranium recovery or removal from aqueous solution (Jin et al., 2018; Li et al., 2019a), due to its simple preparation process, lower price, higher temperature resistance, radiation resistance, higher stability to almost all kinds of acidic and alkali environments, nontoxic, and environmentally friendly nature (Zhao et al., 2017; Pu et al., 2019).

Generally, excess sludge (ES) was applied for biochar preparation (Li et al., 2019b; Hu et al., 2019). ES is mainly generated by wastewater treatment plant (WWTP) with large yield (Ghosh, 2009; Ali et al., 2019). It is difficult to treat ES, and its post-processing cost is relatively high (Hossain et al., 2018). Moreover, secondary pollution might easily happen if ES is not properly treated (Sun et al., 2018). Kanterli reported that sludge-based biochar (SBB) showed high sorption capacity $(112.40 \mathrm{mg} / \mathrm{g}$ ) for $\mathrm{Cr}(\mathrm{VI})$ (Ismail Cem and Jale, 2009). SBB prepared from municipal sludge $(11.27 \mathrm{mg} / \mathrm{g})$ and papermaking sludge $(11.78 \mathrm{mg} / \mathrm{g})$ by hydrothermal treatment had good sorption capacity for $\mathrm{Pb}$ (II) removal, too (Alatalo et al., 2013). In addition, $\mathrm{SBB}$ and $\mathrm{Fe}_{3} \mathrm{O}_{4^{-}}$ modified SBB also showed high uranium ion sorption efficiency (more than 90.0\%) (Zeng et al., 2020; Guanhai et al., 2021). What is more, the treatment of UCW by SBB cannot only effectively solve the problem from ES, but also achieve the effect of waste treatment fee and waste resource utilization. However, to make SBB more practical, its sorption capacity for uranium or other heavy metals needs to be further improved.
So far, the most effective method for improving biochar sorption capacity or removal rate of heavy metals is to increase specific surface area or functional groups on its surface. For example, the effect of nitric acid on the surface area enlargement of biochar has been reported (Ioanna et al., 2017; Mishra et al., 2017). In addition, oxygen functional groups (Anirudhan and Deepa, 2015), humus (Zong et al., 2015), amine (Zhao et al., 2015), amino amine (Deb et al., 2012), dopaminer (Wu et al., 2017), and oximer (Xiong et al., 2017) were considered as corresponding functional groups to improve heavy metal removal rate. $-\mathrm{COOH}$, as a representative of oxygen functional groups, is suitable for the complexation of uranium ions (Park et al., 2019). However, there is still a lack of research on the simultaneous expansion of pores and the addition of groups to recover more uranium ions in SBB.

In order to achieve the above requirements, the removal and recovery efficiency of uranium from UCW was comprehensively studied by involving acetic acid-modified SBB (ASBB) prepared from ES and acetic acid, including 1) differences in uranium recovery efficiency from UCW when SBB or ASBB were used, 2) impacts of variety factors (reaction time, $\mathrm{pH}$, dosage, initial concentration, desorption, and interfering ions) on uranium removal by ASBB, 3) kinetic and thermodynamic analysis of sorption, 4) ASBB uranium removal mechanism based on Brunauer-Emmett-Teller (BET), scanning electron microscopy (SEM), energy-dispersive x-ray spectroscopy (EDS), Fouriertransform infrared spectroscopy (FTIR), and $\mathrm{x}$-ray photoelectron spectroscopy (XPS) techniques. In this paper, acetic acid was used as a modifier to modify SBB and to treat UCW. This modification method could also be used to treat other heavy metal ions in the future.

\section{MATERIALS AND METHODS}

\section{Starting Materials}

ES was obtained from a WWTP located in Hengyang, China. The reagents used in this study were of analytical grade. Chloroacetic acid $\left(\mathrm{CH}_{2} \mathrm{ClCOOH}\right)$, hydrochloric acid $(\mathrm{HCl})$, ferrous sulfate heptahydrate $\left(\mathrm{FeSO}_{4} .7 \mathrm{H}_{2} \mathrm{O}\right)$ and sodium hydroxide $(\mathrm{NaOH})$, potassium hydroxide $(\mathrm{KOH})$, and acetic acid $\left(\mathrm{CH}_{3} \mathrm{COOH}\right)$ were purchased from Sinopharm Group Pharmaceutical Co., Ltd. (Shanghai). Arsenio III $\left[(\mathrm{HO})_{2} \mathrm{C}_{10} \mathrm{H}_{2}\left(\mathrm{SO}_{3} \mathrm{H}\right)_{2}\left(\mathrm{~N}=\mathrm{NC}_{6} \mathrm{H}_{4} \mathrm{AsO}_{3} \mathrm{H}_{2}\right)_{2}\right]$ and triuranium octoxide $\left(\mathrm{U}_{3} \mathrm{O}_{8}\right)$ were purchased from Tianjin Kemio Chemical Reagent Co., Ltd., and China Academy of Metrology, respectively.

Uranium stock solution $(1.0 \mathrm{~g} / \mathrm{L})$ was prepared by dissolving $\mathrm{U}_{3} \mathrm{O}_{8}$ in concentrated nitric acid. The specific preparation process was as follows: First, the dried $1.1792 \mathrm{~g} \mathrm{U}_{3} \mathrm{O}_{8}$ powder was accurately weighed into a $100-\mathrm{ml}$ beaker. Second, $10.0 \mathrm{ml}$ of hydrochloric acid solution with a density of $1.18 \mathrm{~g} / \mathrm{cm}^{3}, 3.0 \mathrm{ml}$ of $30 \mathrm{wt} \%$ hydrogen peroxide, and two drops of $1.0 \mathrm{mg} / \mathrm{L}$ of nitric acid solution were sequentially added to the beaker. Then the beaker was covered with a lid for $3 \mathrm{~min}$. After time had elapsed, the solution was stirred by a glass rod for several minutes. After a violent reaction was completed, the beaker was moved a the 


\section{(a)}

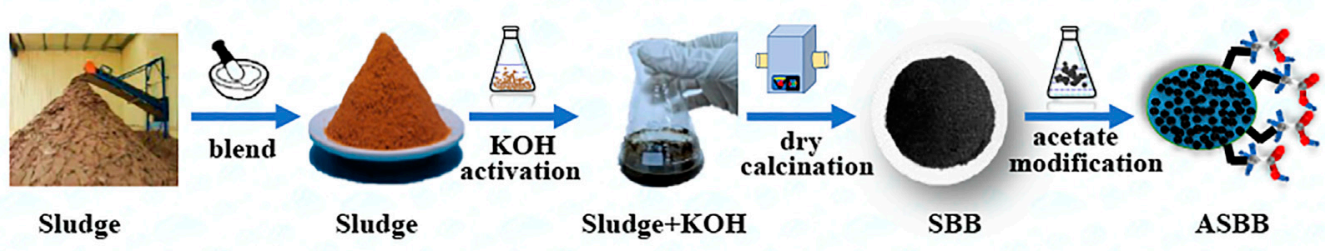

(b)

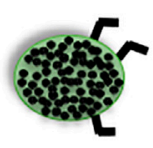

SBB or ASBB
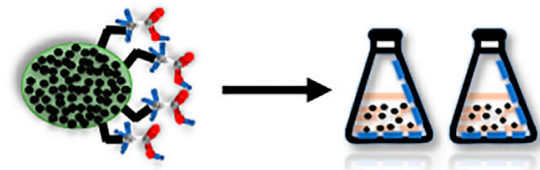

$\mathrm{UCW}+(\mathrm{SBB}$ or $\mathrm{ASBB})$
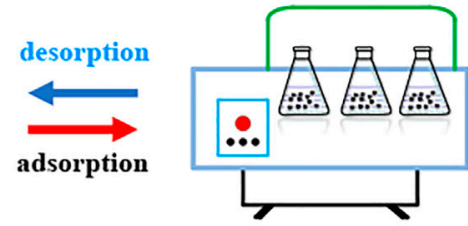

Constant temperature water bath vibration certain

FIGURE 1 | Preparation of sludge-based biochar (SBB) and acid-modified sludge-based biochar (ASBB) and uranium recovery from uranium-containing wastewater (UCW). (A) Preparation of SBB and ASBB. (B) Uranium recovery from UCW by SBB or ASBB.

graphite heating plate for heating and dissolution. When the dissolution was completed, the solution was cooled to room temperature. Finally, the solution was transferred to a $1,000.0-$ $\mathrm{ml}$ volumetric flask, and a nitric acid solution with $\mathrm{pH}<2$ was used for constant volume. More information in detail could be found in cited literature (Lu et al., 2018a). All concentrations of UCW solutions used in the experiment were diluted by $1.0 \mathrm{~g} / \mathrm{L}$ uranium stock solution.

\section{Sludge-Based Biochar and Acetic Acid-Modified SBB Preparation}

The preparation process of SBB and ASBB is shown in Figure 1A. The dewatered ES was collected from WWTP and then dried at $105^{\circ} \mathrm{C}$ for $24 \mathrm{~h}$. The dried ES was impregnated with $\mathrm{KOH}$ $(3.0 \mathrm{~mol} / \mathrm{L})$ in proportion to mass and activated for $24 \mathrm{~h}$. The impregnated $\mathrm{ES}$ was again dried at $80^{\circ} \mathrm{C}$ in a constant temperature drying oven. Thereafter, it was pyrolyzed to biochar in a muffle furnace at $350^{\circ} \mathrm{C}-700^{\circ} \mathrm{C}$ for $40-50 \mathrm{~min}$ under nitrogen atmosphere. Biochar was cooled down to room temperature under nitrogen atmosphere. Then it was washed to neutral by distilled water. The production rate of fresh SBB was $86.0 \pm 10.0 \%$. The biochar was immersed in $\mathrm{CH}_{3} \mathrm{COOH}$ solution $(36.0 \%-38.0 \%)$ for $6 \mathrm{~h}$ and then washed with distilled water to neutrality, thus, eventually getting ASBB.

\section{Experimental setup}

\section{Orthogonal Experiments}

Figure 1B displays the rationale of the experiments of uranium recovered from UCW with different SBB or ASBB dosages. A certain amount of SBB or ASBB was added to $100.0 \mathrm{ml}$ of U(VI) solution. Temperature and stir speed were kept at $25^{\circ} \mathrm{C}$ and $120 \mathrm{r} /$ min, respectively. The removal efficiencies of $\mathrm{U}(\mathrm{VI})$ by fresh SBB and ASBB were investigated according to orthogonal experiments. They were conducted under different mass ratios of sludge/KOH (MSK), calcination temperature (CTE), calcination time (CTI), and activation time (AT) (Table 1). Initial $\mathrm{U}(\mathrm{VI})$ concentration in UCW was $10.0 \mathrm{mg} / \mathrm{L}$, $\mathrm{pH}$ was 3.03 , and the dosage of fresh SBB or ASBB was $0.50 \mathrm{~g} / \mathrm{L}$ in each investigated case.

\section{Batch Experiment}

Several values of reaction time $(1.0,2.0,3.0,4.0,5.0,10.0,20.0$, and $30.0 \mathrm{~min})$, initial $\mathrm{pH}$ (3.0-9.0 with a minimum interval of $1.0)$, adsorbent dosage $(0.05,0.1,0.1,0.3,0.4$, and $0.5 \mathrm{~g} / \mathrm{L})$, and initial uranium ion concentration $(5.0,10.0,20.0,30.0,50.0$, and $100.0 \mathrm{mg} / \mathrm{L}$ ) were scrutinized. U(VI) concentration in artificial UCW was kept at $10.0 \mathrm{mg} / \mathrm{L}$ except for particular cases. Dosage of SBB or ASBB was $0.30 \mathrm{~g} / \mathrm{L}$, and $\mathrm{pH}$ was 6.0.

The desorption of ASBB was carried out by utilizing $\mathrm{HCl}$ $(2.0 \mathrm{~mol} / \mathrm{L})$ as a desorption agent. The interference test of the sorption of $\mathrm{U}(\mathrm{VI})$ by coexisting ions (cation) in the solution was also carried out. Except for the solution containing $10.0 \mathrm{mg} / \mathrm{L}$ of $\mathrm{U}(\mathrm{VI})$, the concentration of coexisting ions in each solution was simulated to $10.0 \mathrm{mg} / \mathrm{L}$. The interfering ions involved were $\mathrm{Fe}^{3+}, \mathrm{Na}^{+}, \mathrm{Mg}^{2+}, \mathrm{Pb}^{2+}$, and $\mathrm{Cr}^{6+}$. During the test, two dosages ( 0.3 and $0.5 \mathrm{~g} / \mathrm{L})$ of ASBB were set. $\mathrm{HCl}(0.01 \mathrm{~mol} /$ L) and $\mathrm{NaOH}(0.01 \mathrm{~mol} / \mathrm{L})$ were used for adjusting $\mathrm{pH}$ of artificial UCW.

\section{Analysis and Characterization}

$\mathrm{U}(\mathrm{VI})$ concentration was determined by Arsenazo III spectrophotometer (Ding et al., 2018). The absorbance of UCW was measured at a wavelength of $652 \mathrm{~nm}$ after 
TABLE 1 | Effect of biochar on uranium-containing wastewater (UCW) treatment under different preparation conditions.

\begin{tabular}{|c|c|c|c|c|c|c|c|c|}
\hline \multirow[t]{2}{*}{ Influencing factors } & \multirow{2}{*}{$\frac{\text { Sludge: KOH }}{\text { MSK }}$} & \multirow{2}{*}{$\begin{array}{l}\text { Calcination temperature }\left({ }^{\circ} \mathrm{C}\right) \\
\text { CTE }\end{array}$} & \multirow{2}{*}{$\begin{array}{l}\text { Calcination time (min) } \\
\text { CTI }\end{array}$} & \multirow{2}{*}{$\frac{\text { Activation time (h) }}{\text { AT }}$} & \multicolumn{2}{|c|}{$\begin{array}{l}\text { Removal } \\
\text { rate }(\%)\end{array}$} & \multicolumn{2}{|c|}{$\begin{array}{c}\text { Sorption } \\
\text { capacity } \\
(\mathrm{mg} / \mathrm{g})\end{array}$} \\
\hline & & & & & SBB & ASBB & SBB & ASBB \\
\hline Exp 1 & $3: 1$ & 400 & 30 & 3 & 23.6 & 42.8 & 4.72 & 8.56 \\
\hline Exp 2 & $2: 1$ & 400 & 40 & 6 & 28.1 & 52.2 & 5.62 & 10.44 \\
\hline Exp 3 & $1: 1$ & 400 & 50 & 12 & 39.3 & 67.3 & 7.86 & 13.46 \\
\hline Exp 4 & $1: 2$ & 400 & 60 & 24 & 39.9 & 68.9 & 7.98 & 13.78 \\
\hline Exp 5 & $1: 3$ & 400 & 70 & 48 & 40.8 & 70.8 & 8.16 & 14.16 \\
\hline Exp 6 & $3: 1$ & 450 & 40 & 12 & 30.6 & 48.6 & 6.12 & 9.72 \\
\hline Exp 7 & $2: 1$ & 450 & 50 & 24 & 38.7 & 58.3 & 7.74 & 11.66 \\
\hline Exp 8 & $1: 1$ & 450 & 60 & 48 & 45.2 & 75.1 & 9.04 & 15.02 \\
\hline Exp 9 & $1: 2$ & 450 & 70 & 3 & 46.3 & 76.2 & 9.26 & 15.24 \\
\hline Exp 10 & $1: 3$ & 450 & 30 & 6 & 45.1 & 77.5 & 9.02 & 15.5 \\
\hline Exp 11 & $3: 1$ & 500 & 50 & 48 & 35.1 & 51.2 & 7.02 & 10.24 \\
\hline Exp 12 & $2: 1$ & 500 & 60 & 3 & 43.1 & 63.1 & 8.62 & 12.62 \\
\hline Exp 13 & $1: 1$ & 500 & 70 & 6 & 52.2 & 83.1 & 10.44 & 16.62 \\
\hline Exp 14 & $1: 2$ & 500 & 30 & 12 & 52.5 & 83.6 & 10.5 & 16.72 \\
\hline Exp 15 & $1: 3$ & 500 & 40 & 24 & 53.2 & 84.1 & 10.64 & 16.82 \\
\hline Exp 16 & $3: 1$ & 550 & 60 & 6 & 42.8 & 55.8 & 8.56 & 11.16 \\
\hline Exp 17 & $2: 1$ & 550 & 70 & 12 & 56.2 & 77.2 & 11.24 & 15.44 \\
\hline Exp 18 & $1: 1$ & 550 & 30 & 24 & 57.8 & 87.1 & 11.56 & 17.42 \\
\hline Exp 19 & $1: 2$ & 550 & 40 & 48 & 58.6 & 87.2 & 11.72 & 17.44 \\
\hline Exp 20 & $1: 3$ & 550 & 50 & 3 & 58.9 & 87.4 & 11.78 & 17.48 \\
\hline Exp 21 & $3: 1$ & 600 & 70 & 24 & 45.1 & 53.1 & 9.02 & 10.62 \\
\hline Exp 22 & $2: 1$ & 600 & 30 & 48 & 60.7 & 83.9 & 12.14 & 16.78 \\
\hline Exp 23 & $1: 1$ & 600 & 40 & 3 & 61.2 & 87.9 & 12.24 & 17.58 \\
\hline Exp 24 & $1: 2$ & 600 & 50 & 6 & 61.6 & 88.1 & 12.32 & 17.62 \\
\hline Exp 25 & $1: 3$ & 600 & 60 & 12 & 62.3 & 87.9 & 12.46 & 17.58 \\
\hline$F$ & 87.09 & 9.84 & 4.34 & 1.18 & & & & \\
\hline$P$ & $<0.0001$ & 0.0106 & 0.0638 & 0.3034 & & & & \\
\hline
\end{tabular}

Note. The F value represents the significance of the whole fitting equation, and the larger the $F$ implies the more significant the equation, and the better the fitting degree. $\mathrm{p}$-Value is a parameter used to determine the hypothesis test results. The smaller the $\mathrm{p}$-value means the more significant the result. KOH, potassium hydroxide; SBB, sludge-based biochar; ASBB, acid-modified sludge-based biochar; AT, activation time; CTI, calcination time; CTE, calcination temperature; MSK, mass ratio of sludge/KOH.

preheating the spectrophotometer for $30 \mathrm{~min}$. Inductively coupled plasma-mass spectrometry (ICP-MS) was used to double check the values obtained from spectrophotometry. The difference in the results obtained with the two methods was $1.47 \%-1.53 \%$, indicating that spectrophotometry was a reliable method under these operating conditions.

The uranium equilibrium specific sorption capacity $q_{e}(\mathrm{mg} / \mathrm{g})$ and removal rate $\eta$ for each sorbent (SBB or ASBB) were calculated according to Eqs. 1 and 2, respectively (Liu et al., 2018):

$$
\begin{gathered}
q_{e}=\frac{\nu\left(c_{0}-c_{e}\right)}{m} \\
\eta=\frac{c_{0}-c_{e}}{c_{e}}
\end{gathered}
$$

where $c_{0}$ and $c_{e}$ are the initial and equilibrium concentrations of uranium in the solution, $v$ is the solution volume, and $m$ is the mass of adsorbent. Langmuir and Freundlich sorption isotherm models were introduced to fit the $\mathrm{U}(\mathrm{VI})$ sorption data for ASBB under equilibrium conditions (Eqs 3, 4). The equations read, respectively (Christou et al., 2019):

$$
q_{e}=\frac{q_{m} K_{L} C e}{\left(1+K_{L} C e\right)}
$$

$$
q_{e}=K_{F} C e^{\frac{1}{n}}
$$

where $q_{m}$ is the maximum specific sorption capacity, $K_{L}$ is the Langmuir equilibrium constant $(\mathrm{L} / \mathrm{mg})$, while $K_{F}$ and $n$ are the Freundlich parameters, respectively, representing the sorption capacity and the sorption intensity.

In order to investigate in detail the $\mathrm{U}(\mathrm{VI})$ sorption process by ASBB, kinetic data were fitted by pseudo-first-order (Lagergren PFO, Eq. 5) and pseudo-second-order (Ho\&McKay PSO, Eq. 6) models. The equations read, respectively (Li et al., 2018):

$$
\begin{gathered}
q_{t}=q_{e}\left[1-\exp \left(-\kappa_{1} t\right)\right] \\
q_{t}=\frac{\kappa_{2} q_{e}^{2} t}{1+\kappa_{2} q_{e} t}
\end{gathered}
$$

where $q_{t}$ refers to the specific sorption capacity at $t$ time, $\kappa_{1}$ is the PFO sorption rate constant $\left(\mathrm{min}^{-1}\right)$, and $\kappa_{2}$ is the PSO sorption rate constant $\left(\mathrm{g} / \mathrm{mg} \cdot \mathrm{min}^{-1}\right)$.

To compare the content of acidic functional groups on the surface of SBB, ASBB, and acetic acid-modified sludge-based biochar-uranium (ASBB-U), the contents of $-\mathrm{OH},-\mathrm{COO}$, and $-\mathrm{COOH}$ were determined by the Boehm method (Kalijadis et al., 2011). Three samples of $1.0 \mathrm{~g}$ of each material were accurately weighed, and the samples were put into $100.0-\mathrm{ml}$ conical flasks. 

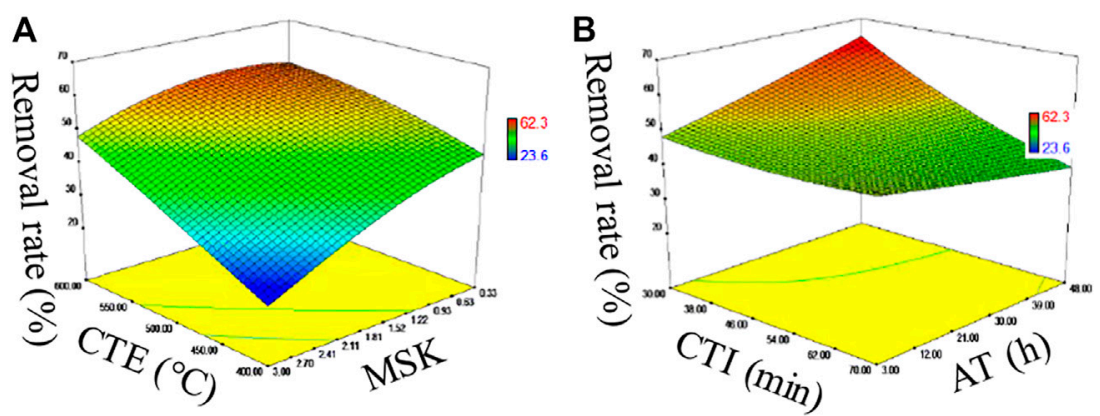

FIGURE 2 | (A) Uranium sorption from SBB and ASBB impacted by calcination temperature (CET) and sludge: KOH (MSK), (B) Uranium sorption from SBB and ASBB impacted by calcination time (CTI) and activation time (AT).

Then three samples of each material were added to $25.0 \mathrm{ml}$ of $0.05 \mathrm{~mol} / \mathrm{L} \mathrm{NaOH}, \mathrm{Na}_{2} \mathrm{CO}_{3}$, and $\mathrm{NaHCO}_{3}$ standard solution, respectively. Nine samples were all stirred for a 24 -h reaction and then filtered. During filtration, they were fully washed with distilled water. All the filtrates were collected independently. Methyl red was used as the end indicator of the filtrate. The unreacted alkali in the filtrate was titrated to end by a standard solution of $0.05 \mathrm{~mol} / \mathrm{L}$ of $\mathrm{HCl}$. The content of $-\mathrm{OH},-\mathrm{COO}$, and $-\mathrm{COOH}$ was calculated by the amount of $\mathrm{HCl}$.

The existing forms of uranium in UCW $(10.0 \mathrm{mg} / \mathrm{L})$ and $\mathrm{P}_{\mathrm{CO} 2}=10^{-3.5} \mathrm{~atm}$ under $\mathrm{pH}$ from 3.0 to 9.0 were simulated by Visual MINTEQ 3.1 (Schierz and Zänker, 2009; Zong et al., 2017). The specific surface area of fresh or used SBB and ASBB was determined by BET technique (TriStar II Plus 2.02, Micromeritics, USA). The morphology of fresh or used SBB and ASBB was characterized by SEM (JSM-7500F, JEOL, JPN) coupled with EDS (INCA, Oxford, USA). Functional groups on fresh or used SBB and ASBB were analyzed through FTIR (Nicolet-iS50, Thermo Fisher Scientific, USA). The composition and chemical states of ASBB after UCW sorption were examined by XPS (Escalab 250Xi, Thermo Fisher Scientific, United States) with AlKa radiation. The binding energies were calibrated by using containment carbon $(\mathrm{C} 1 \mathrm{~s}=284.7 \mathrm{eV})$. The data analysis was carried out via Casa XPS software (Version 2.3.13).

\section{RESULTS AND DISCUSSION}

\section{Comparison Between Sludge-Based Biochar and Acetic Acid-Modified Sludge-Based Biochar in Uranium-Containing Wastewater Sorption}

The performance of $\mathrm{U}(\mathrm{VI})$ removal is presented in Figure 2. The removal rate of $\mathrm{U}(\mathrm{VI})$ by fresh SBB and ASBB gradually increased with the decrease in MSK and with the increase in CTE (Figure 2A), CTI (Figure 2B), and AT. The $F$ values of MSK, CTE, CTI, and AT were 87.09, 9.84, 4.34, and 1.18, respectively, (refer to Table 1). The $p$-values were $<0.0001,0.0106,0.0638$, and
0.3034 , respectively. These results indicate that the influence ranking of the explored parameters is MSK, CTE, CTI, and AT. In particular, MSK had an extremely significant effect, and CTE showed a similar tendency (Anna et al., 2018). In addition, the removal rate and sorption capacity of ASBB were higher than SBB, indicating that acetic acid modification of the biochar showed excellent effect on U(VI) removal. Altogether, the optimal preparing conditions for fresh SBB and ASBB are suggested as: $\quad \mathrm{MSK}=1: 1, \quad \mathrm{CTE}=550^{\circ} \mathrm{C}, \quad \mathrm{CTI}=30 \mathrm{~min}$, and $\mathrm{AT}=24 \mathrm{~h}$.

\section{U(VI) Removal Efficiencies by Acetic Acid-Modified Sludge-Based Biochar Under Different Conditions \\ Reaction Time}

Figure 3A depicts the removal rate of $U(V I)$ as a function of time for SBB and ASBB. The removal rate of U(VI) by SBB and ASBB increased with time quickly, and the sorption equilibrium was practically achieved within $5.0 \mathrm{~min}$. This phenomenon was mainly due to the high $\mathrm{U}(\mathrm{VI})$ concentration, and to the large number of sorption sites made available by SBB and ASBB. U(VI) could rapidly diffuse to the adsorbent particle due to the high concentration gradient, to be then adsorbed on the solid surface-active sites. However, the removal rate and sorption capacity of $\mathrm{U}(\mathrm{VI})$ were close to the peak after $5.0 \mathrm{~min}$. Two main reasons could explain this observation. First, the U(VI) concentration in the solution was quite low, and the U(VI) concentration was considered as one main limiting factor for the improvement of $\mathrm{U}(\mathrm{VI})$ removal rate. Second, the surface sorption sites decreased as the reaction proceeds. The probability of $\mathrm{U}(\mathrm{VI})$ binding to sorption sites was then decreased. As shown in Figure $\mathbf{3 A}$, the U(VI) removal rate by $\mathrm{SBB}$ and $\mathrm{ASBB}$ was $62.8 \%$ and $97.8 \%$, respectively. Meanwhile, the specific sorption capacity of these two adsorbents was 20.9 and $32.6 \mathrm{mg} / \mathrm{g}$, respectively. The sorption capacity of $\mathrm{U}(\mathrm{VI})$ by $\mathrm{ASBB}$ was $55.8 \%$ higher than that of SBB. These results showed that ASBB could adsorb 

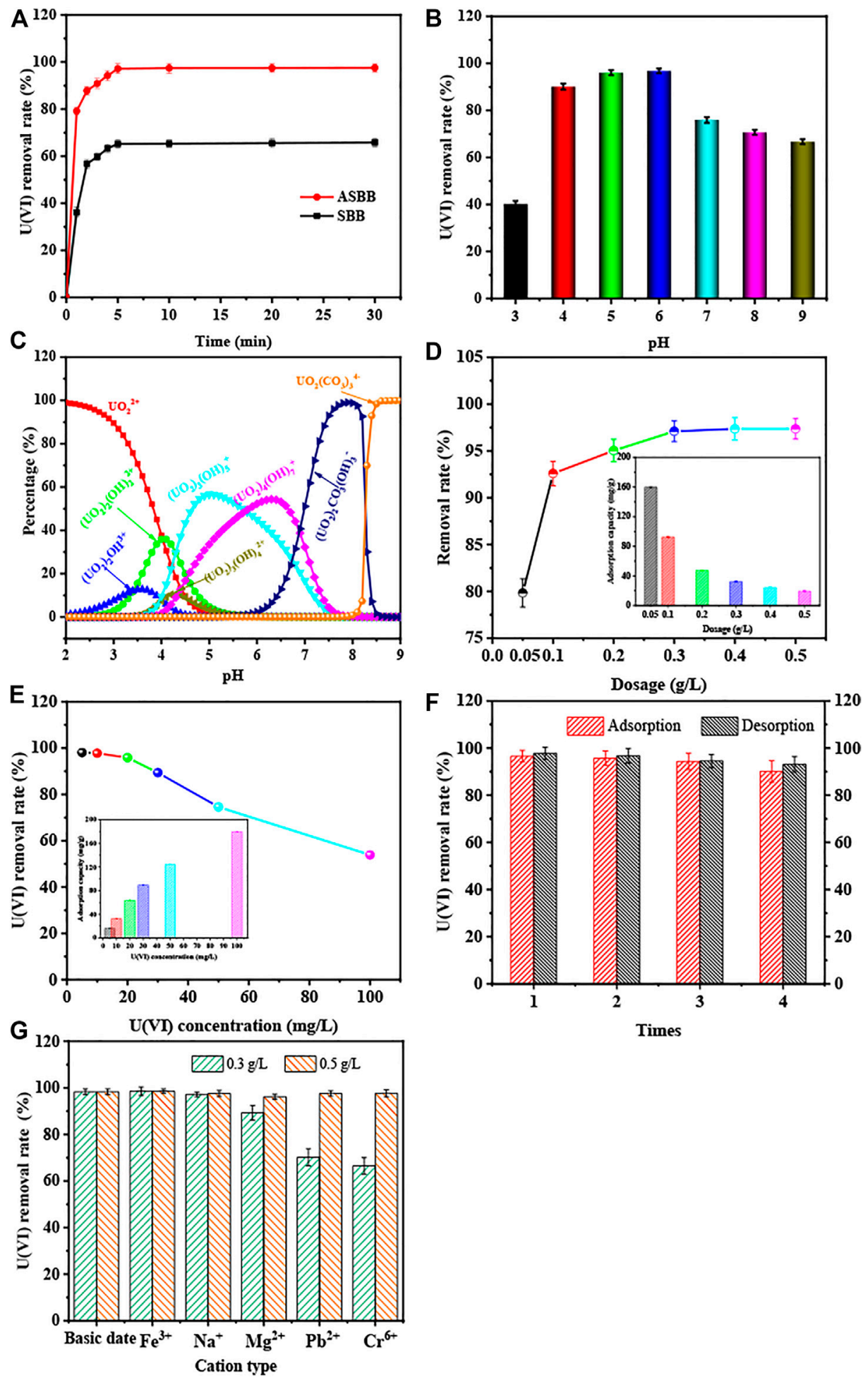

FIGURE 3 | Sorption rate of U(VI) by SBB or ASBB under different conditions. (A) Reaction time of SBB or ASBB for U(VI) sorption, (B) U(VI) sorption by ASBB under difference initial pH of USW, (C) simulation calculation of the existing state of uranium ions under different pH conditions, (D) removal rate of uranium in USW by ASBB under different dosage, (E) the removal rate of uranium ions by ASBB at different initial concentrations of USW, (F) desorption efficiency of uranium ions by ASBB, (G) effect of interfering ions on sorption of uranium ions by ASBB in USW. 
$\mathrm{U}(\mathrm{VI})$ more rapidly and efficiently, and the sorption equilibrium could be achieved within $5.0 \mathrm{~min}$.

\section{Initial $\mathrm{pH}$ of Aqueous Solution}

Figures 3B, C illustrate the experimental and simulation results of the influences of the initial $\mathrm{pH}$ value of the aqueous solution. Figure 3B shows that sorption of U(VI) from ASBB was greatly influenced by $\mathrm{pH}$. Figure 3C displays that the existing uranium morphology varies under different $\mathrm{pH}$ conditions. The main morphologies were $\mathrm{UO}_{2}{ }^{2+}$, $\left(\mathrm{UO}_{2}\right)_{2}(\mathrm{OH})_{2}{ }^{2+}, \quad\left(\mathrm{UO}_{2}\right)_{2} \mathrm{OH}^{3+}, \quad\left(\mathrm{UO}_{2}\right)_{3}(\mathrm{OH})_{5}{ }^{+}, \quad\left(\mathrm{UO}_{2}\right)_{3}(\mathrm{OH})_{4}{ }^{2+}$, $\left(\mathrm{UO}_{2}\right)_{4}(\mathrm{OH})_{7}{ }^{+}, \mathrm{UO}_{2}\left(\mathrm{CO}_{3}\right)_{3}{ }^{4-}$, and $\left(\mathrm{UO}_{2}\right)_{2} \mathrm{CO}_{3}(\mathrm{OH})_{3}{ }^{-}$. The U(VI) removal rate was only $42.4 \%$ when $\mathrm{pH}=3.0$, where uranium mainly exists in the form of $\mathrm{UO}_{2}{ }^{2+}$ in UCW. Because the solution $\mathrm{pH}$ value was in this case too low, a lot of $\mathrm{H}^{+}$competed with $\mathrm{UO}_{2}{ }^{2+}$ sorption. Meanwhile, an $\mathrm{H}^{+}$proton layer on the surface of ASBB could be formed, rather than $\mathrm{UO}_{2}{ }^{2+}$. The electrostatic repulsion of ASBB to $\mathrm{UO}_{2}{ }^{2+}$ might increase; thus, the removal rate of uranium was relatively low (Wu et al., 2019). When the $\mathrm{pH}$ was between 4.0 and 6.0, the uranium in solution mainly existed in the form of $\left(\mathrm{UO}_{2}\right)_{2}(\mathrm{OH})_{2}{ }^{2+}, \quad\left(\mathrm{UO}_{2}\right)_{3}(\mathrm{OH})_{5}{ }^{+}, \quad\left(\mathrm{UO}_{2}\right)_{4}(\mathrm{OH})_{7}{ }^{+}$. The low protonation degree of these forms favored the sorption of uranium by ASBB (Zhu et al., 2018). With the increase in $\mathrm{pH}$, many organic functional groups (such as $-\mathrm{OH},-\mathrm{COOH}$, etc.) might be gradually assembled on the surface of ASBB. $\mathrm{H}^{+}$on these groups then decreased, so the electronegativity of these groups increased. The binding ability and reaction probability between functional groups and uranium increased due to this phenomenon. The uranium removal rate increased under this condition. When $\mathrm{pH}$ was 6.0, the U(VI) removal rate peak was $97.2 \%$. When $\mathrm{pH}$ was between 7.0 and 9.0, the uranium was mainly in the form of $\mathrm{UO}_{2}\left(\mathrm{CO}_{3}\right)_{3}{ }^{4-}$ and $\left(\mathrm{UO}_{2}\right)_{2} \mathrm{CO}_{3}(\mathrm{OH})_{3}{ }^{-}$. These forms were difficult to be adsorbed by ASBB, and the removal rate of uranium was reduced. Therefore, $\mathrm{pH}=6.0$ was suggested as the optimal condition for $\mathrm{U}(\mathrm{VI})$ sorption from UCW by ASBB.

\section{Dosage of Acetic Acid-Modified Sludge-Based Biochar}

Figure 3D shows the effect of different ASBB dosages on U(VI) removal. The initial U(VI) concentration was $10.0 \mathrm{mg} / \mathrm{L}$. The U(VI) removal rate increased from $79.8 \%$ to $97.8 \%$ when the dosage of ASBB increased from 0.05 to $0.5 \mathrm{~g} / \mathrm{L}$. With the increase in the dosing amount, the reaction sites of ASBB in UCW increased as well. The probability of $\mathrm{U}(\mathrm{VI})$ to interact with reaction sites, therefore, increased and the $\mathrm{U}(\mathrm{VI})$ removal efficiency was improved. In general, $0.30 \mathrm{~g} / \mathrm{L}$ was determined as the optimal dosage used in further sections also taking into account economic reasons.

\section{Initial U(VI) Concentration}

Figure 3E illustrates the sorption capacity of ASBB and uranium removal rate under different initial $U(V I)$ concentrations in the wastewater recovered by ASBB biochar. When the dosage of ASBB was $0.30 \mathrm{~g} / \mathrm{L}$, the UCW removal rate result is equal to $98.1 \%$ (initial concentration $=5.0 \mathrm{mg} / \mathrm{L}$ ) and $97.8 \% \quad$ (initial concentration $=10.0 \mathrm{mg} / \mathrm{L})$. Namely, with the increase in $\mathrm{U}(\mathrm{VI})$ initial concentration, the removal rate of $\mathrm{U}(\mathrm{VI})$ by ASBB gradually decreased, while the specific sorption capacity was increased. The latter might be due to the excess U(VI) in the system, that drives the sorption process. Moreover, when the dosage of ASBB was $3.0 \mathrm{~g} / \mathrm{L}$ (i.e., one order of magnitude higher), the removal efficiency for $100.0 \mathrm{mg} / \mathrm{L}$ of uranium concentration in UCW was $95.7 \%$. These results demonstrated that ASBB was not only suitable for the uranium recovery from UCW with low uranium concentration but also for high concentration values. In addition, Table 2 shows the results for different adsorbents. The $\mathrm{U}(\mathrm{VI})$ sorption capacity of ASBB per unit time was about $10-1,000$ times that of other materials, indicating that ASBB was a rapid and efficient $\mathrm{U}(\mathrm{VI})$ adsorbent, with interesting industrial perspectives.

\section{Desorption From Acetic Acid-Modified Sludge-Based Biochar}

The desorption performance of an adsorbent is an important standard to judge whether it can be practically used. Research has shown that adsorbed $\mathrm{U}(\mathrm{VI})$ could be replaced by $\mathrm{H}^{+}$through ion exchange (Wen et al., 2016), and then dissolved in acidic solution (Tu et al., 2019). Figure 3F displays the results of uranium desorption from ASBB. It could be seen that after sorption and desorption for several cycles, the removal efficiency of uranium by ASBB remained at $90.2 \%$, while the desorption efficiency from ASBB was 93.0\%. These results showed that ASBB had good reusability potential, and the recovery of $\mathrm{U}(\mathrm{VI})$ could be achieved in practice.

\section{Interfering lons}

Figure 3G shows the interference of coexisting ions on ASBB's sorption of $\mathrm{U}(\mathrm{VI})$. When the dosage of ASBB was $0.30 \mathrm{~g} / \mathrm{L}, \mathrm{Na}^{+}$ had little effect on the removal of U(VI) by ASBB, while it would be inhibited by $\mathrm{Mg}^{2+}, \mathrm{Pb}^{2+}$, and $\mathrm{Cr}^{6+}$. In particular, $\mathrm{Cr}^{6+}$ had the greatest impact on ASBB's sorption of U(VI). The main reason for this phenomenon might be the competitive sorption of these ions and $\mathrm{U}(\mathrm{VI})$ on the surface of ASBB. Unlike these ions, $\mathrm{Fe}^{3+}$ facilitated the $\mathrm{U}(\mathrm{VI})$ removal. The main reason might be that when $\mathrm{pH}=6, \mathrm{Fe}^{3+}$ could be hydrolyzed into $\mathrm{Fe}(\mathrm{OH})_{3}$ colloids (Feng et al., 2013), and $\mathrm{U}(\mathrm{VI})$ could be combined with $\mathrm{Fe}(\mathrm{OH})_{3}$ (Bruno et al., 1995). As a result, the efficiency of ASBB's removal of $\mathrm{U}(\mathrm{VI})$ was improved. When the dosage of ASBB was increased to $0.50 \mathrm{~g} / \mathrm{L}, \mathrm{U}(\mathrm{VI})$ could still be efficiently adsorbed by ASBB under the interference of various ions. Therefore, when there are interfering ions in the solution, it is recommended to increase the dosage of $\mathrm{ASBB}$ or add a certain amount of $\mathrm{Fe}^{3+}$ to improve the removal rate of $\mathrm{U}(\mathrm{VI})$.

\section{Kinetic and Thermodynamic Analysis of Sorption}

Figure 4A and Table 3 show the results of the PFO and PSO models when they were applied to experimental data. The correlation coefficient $R^{2}$ was 0.998 (PFO) and 0.997 (PSO), indicating that both physical and chemical sorption occurred during the sorption of $\mathrm{U}(\mathrm{VI})$ by ASBB.

The results of the thermodynamic analysis are illustrated in Figure 4B and Table 4. The maximum specific sorption capacity was $q_{m}=178.194 \mathrm{mg} / \mathrm{g}$ (ASBB adsorbent), a value 
TABLE 2 | Comparison of the maximum sorption capacities of different adsorbents toward U(VI).

\begin{tabular}{|c|c|c|c|c|c|c|c|}
\hline Adsorbent & U(VI) (mg/L) & Dosage (g/L) & $Q_{\max }(\mathbf{m g} / \mathrm{g})$ & pH & Time (h) & $q_{t} / t[(m g / g) / h]$ & References \\
\hline $\mathrm{Fe}_{3} \mathrm{O}_{4} @ \mathrm{C} @ \mathrm{ASA}$ & 4.76 & 0.6 & 46.20 & 4.00 & 24.00 & 1.91 & Li et al. (2018) \\
\hline $\mathrm{HTC}-\mathrm{COOH}$ & 140.0 & 0.5 & 163.00 & 4.50 & 24.00 & 6.79 & Cai et al. (2017) \\
\hline Activated carbon & 200.0 & 2.5 & 45.24 & 6.00 & 5.00 & 9.05 & Morsy and Hussein, (2011) \\
\hline MAO-chitosan & 480.0 & 1.0 & 117.65 & 6.00 & 5.00 & 23.53 & Zhuang et al. (2018) \\
\hline$P(A O)-g-C T S / B T$ & 100.0 & 2.0 & 49.90 & 8.00 & 1.00 & 49.90 & Anirudhan et al. (2019) \\
\hline SDACA & 100.0 & 8.0 & 105.26 & 5.00 & 2.00 & 52.63 & El-MagiedAbd et al. (2017) \\
\hline PVP/CS & 11.9 & 1.0 & 167.00 & 6.00 & 2.50 & 66.80 & Christou et al. (2019) \\
\hline AO-MWCNTS & 10.0 & 1.0 & 67.90 & 5.00 & 1.00 & 67.90 & Wu et al. (2018) \\
\hline PAF & 10.0 & 1.0 & 115.31 & 5.00 & 1.00 & 115.31 & Saleh et al. (2017) \\
\hline MWCNTs & 25.0 & 0.1 & 83.40 & 6.25 & 0.67 & 124.45 & Ebrahim et al. (2017) \\
\hline P-Fe-CMK-3 & 20.0 & 0.2 & 150.00 & 4.00 & 0.50 & 300.00 & Husnain et al. (2017) \\
\hline ASBB & 10.0 & 0.3 & 179.77 & 6.00 & 0.08 & $2,247.13$ & This work \\
\hline
\end{tabular}
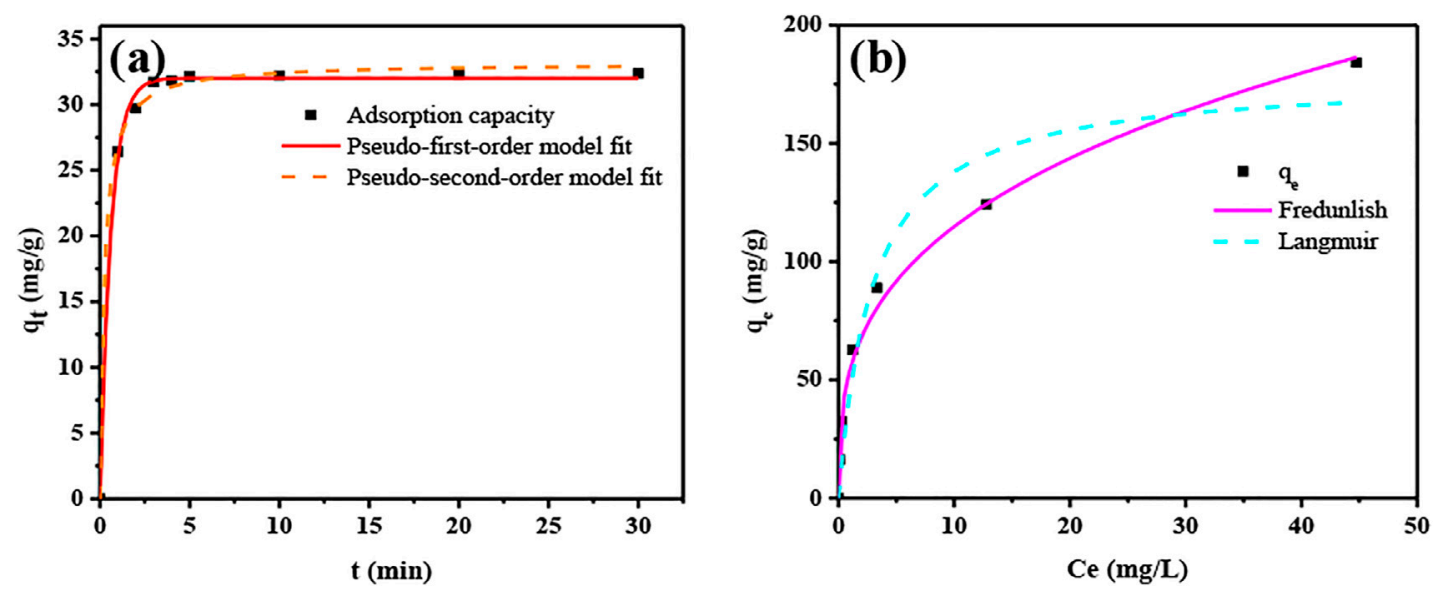

FIGURE 4 | Kinetic and thermodynamic fitted curve. (A) Kinetic fitted curve, (B) thermodynamic fitted curve.

TABLE 3 | Kinetic parameters of U(VI) sorption on ASBB.

U(VI) concentration

(mg/L)

$10.0 \mathrm{mg} / \mathrm{L}$
Pseudo-first-order kinetics

\begin{tabular}{ccc}
\hline $\boldsymbol{k}_{\mathbf{1}} / \mathbf{m i n}^{-\mathbf{1}}$ & $\boldsymbol{q}_{\mathrm{e}} /(\mathbf{m g} / \mathbf{g})$ & $\boldsymbol{R}^{\mathbf{2}}$ \\
1.716 & 31.665 & 0.996
\end{tabular}

Pseudo-second-order kinetics

\begin{tabular}{ccc}
\hline $\boldsymbol{k}_{\mathbf{2}} / \mathbf{m i n}^{-\mathbf{1}}$ & $\boldsymbol{q}_{\mathbf{e}} / \mathbf{( m g / g )}$ & $\boldsymbol{R}^{\mathbf{2}}$ \\
0.126 & 33.087 & 0.999
\end{tabular}

consistent with the laboratory result $q_{m}=179.88 \mathrm{mg} / \mathrm{g}$. The correlation coefficient was 0.943 (Langmuir model) and 0.989 (Freundlich model), indicating that the sorption of $\mathrm{U}(\mathrm{VI})$ by ASBB was mostly dominated by multilayer sorption.

\section{Characterization and Mechanism Analysis of Uranium Recovered by Acetic Acid-Modified Sludge-Based Biochar Morphological Characteristics of Sludge-Based Biochar, Acetic Acid-Modified Sudge-Based Biochar, and Acetic Acid-Modified Sludge-Based Biochar-Uranium}

The microstructure and surface elements of SBB, ASBB, and ASBB-U (i.e., used ASBB adsorbent after uranium sorption) were characterized
TABLE 4 | Thermodynamic parameters of sludge-based biochar on $\mathrm{U}(\mathrm{VI})$ sorption.

\begin{tabular}{|c|c|c|c|c|c|c|}
\hline \multirow[t]{2}{*}{ Adsorbents } & \multicolumn{3}{|c|}{ Langmuir } & \multicolumn{3}{|c|}{ Freundlich } \\
\hline & $q_{m} /(\mathrm{mg} / \mathrm{g})$ & $K_{L} /(\mathrm{L} / \mathrm{mg})$ & $R^{2}$ & $K_{F}$ & $q_{e} /(\mathrm{mg} / \mathrm{g})$ & $R^{2}$ \\
\hline & 178.194 & 0.344 & 0.943 & 54.584 & 0.323 & 0.989 \\
\hline
\end{tabular}

by SEM and EDS (Figure 5). As shown in Figures 5A, C, E, the pore size of the SBB surface was quite small, while a more developed pore structure was presented on the surface of ASBB. More reaction sites could be provided by ASBB to adsorb U(VI). When the sorption was completed, the ASBB microstructure changed. The pore structure of ASBB-U obviously decreased, due to the combination of U(VI) with the functional groups on the ASBB surface, or to the direct sorption of 

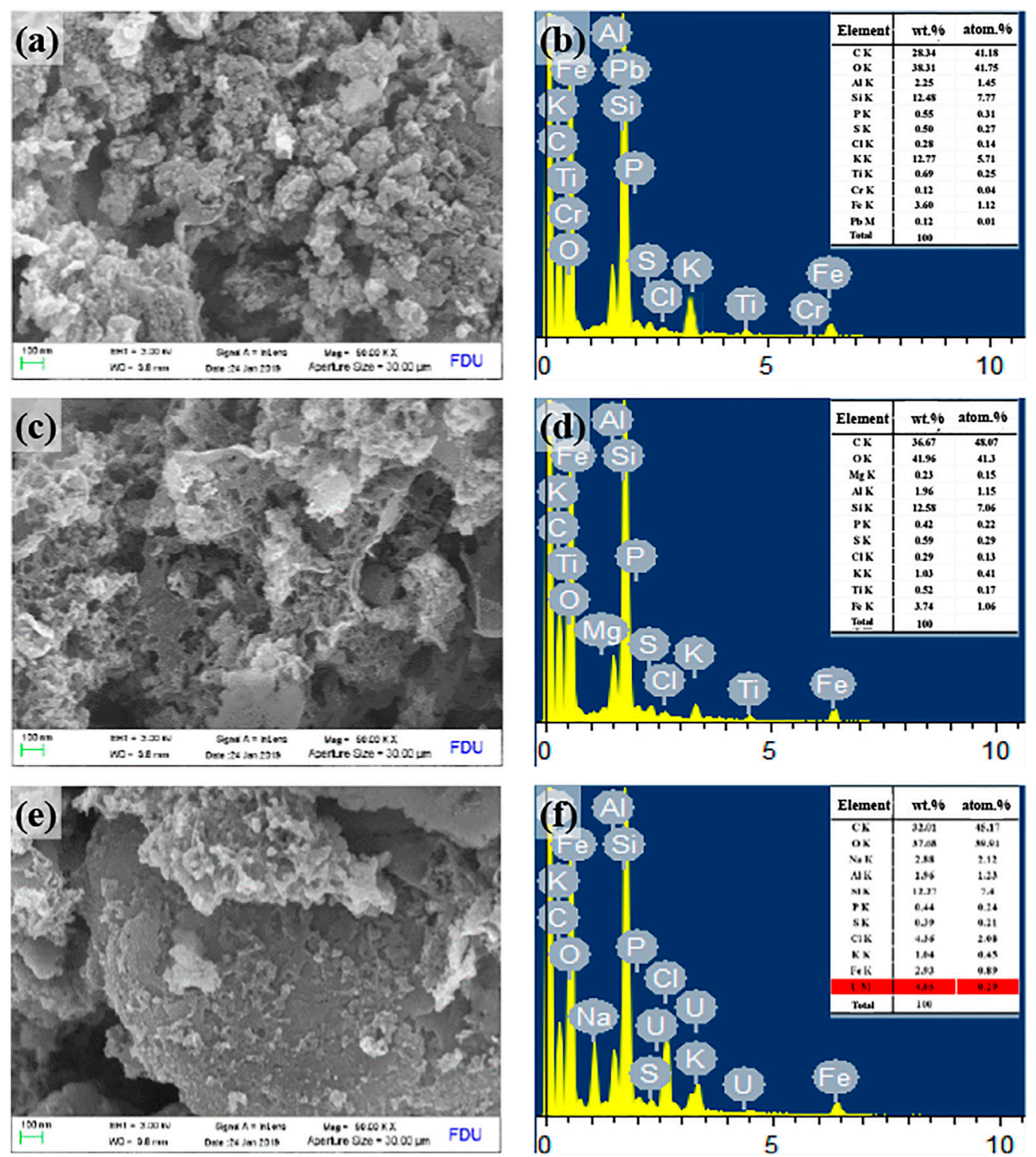

FIGURE 5 | Scanning electron microscope (SEM) and energy-dispersive x-ray spectroscopy (EDS) characterization results of SBB, ASBB, and ASBB-U, (A) SEM of SBB' surface, (B) EDS of SBB' surface, (C) SEM of ASBB' surface, (D) EDS of ASBB' surface, (E) SEM of ASBB-U' surface, (F) EDS of ASBB-U' surface.

$\mathrm{U}(\mathrm{VI})$ in the pore network of ASBB. These results were consistent with the results of BET analysis (vide infra).

According to Figure 5B, the main surface elements of SBB were $\mathrm{C}, \mathrm{O}, \mathrm{K}$, and $\mathrm{Si}$ in general. Figure $5 \mathrm{D}$ shows that the fresh ASBB surface mainly consisted of $\mathrm{C}, \mathrm{O}, \mathrm{Al}, \mathrm{Si}, \mathrm{P}, \mathrm{K}$, and Fe. An amount of $U$ was observed on the ASBB-U surface (Figure 5F). The weight percentage was about $4.05 \mathrm{wt} \%$. This indicated that uranium was successfully adsorbed by ASBB.

\section{Brunauer-Emmett-Teller Comparison of Sludge-Based Biochar, Acetic Acid-Modified Sludge-Based Biochar, and Acetic Acid-Modified Sludge-Based Biochar-Uranium}

Figure 6A and Table 5 show the BET results for SBB, ASBB, and ASBB-U. As in Figure $\mathbf{6 A}$, the isothermal sorption-desorption curves of SBB, ASBB, and ASBB-U all belonged to the unique I/IV isothermal sorption-desorption path with the $\mathrm{H}_{4}$ hysteresis curve (Lu et al., 2018b). It means 

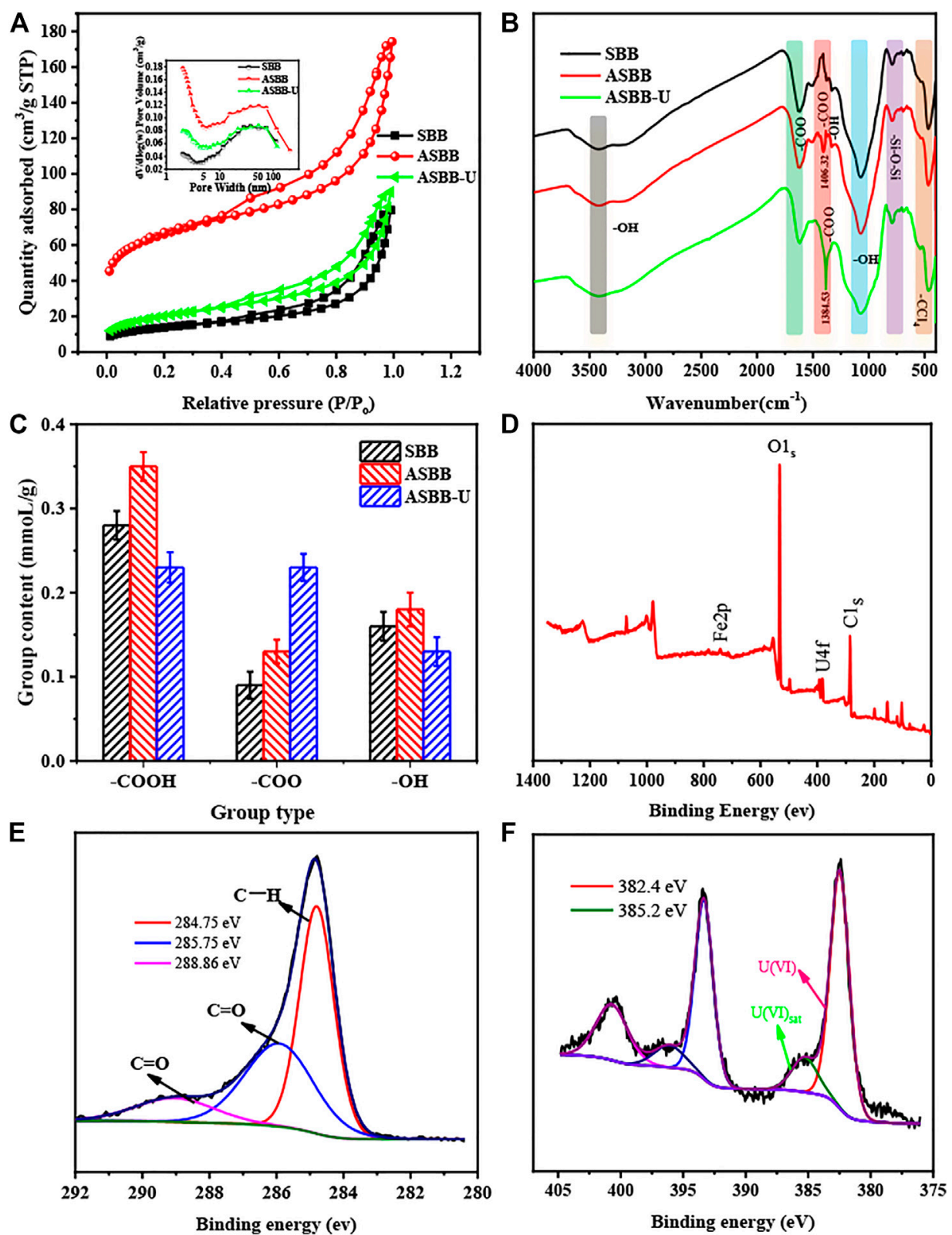

FIGURE 6 | Characteristics of SBB, ASBB, and acetic acid-modified sludge-based biochar-uranium (ASBB-U). (A) Brunner-Emmet-Teller (BET), (B) Fourier transform infrared spectroscopy (FTIR), (C) acidic group content, (D) X-ray photoelectron spectroscopy (XPS) total survey scans of ASBB-U, (E) XPS spectra of C1s, (F) XPS spectra of U4f.

TABLE 5 | Surface aperture analysis.

\begin{tabular}{|c|c|c|c|}
\hline Sample & SSA $\left(\mathrm{m}^{2} / \mathrm{g}\right)$ & Average pore width $(\mathrm{nm})$ & Volume $\left(\mathrm{cm}^{3} / \mathrm{g}\right)$ \\
\hline SBB & 49.26 & 10.00 & 0.12 \\
\hline ASBB & 241.42 & 8.35 & 0.21 \\
\hline ASBB-U & 72.52 & 7.67 & 0.14 \\
\hline
\end{tabular}

Note. SSA, specific surface area; ASBB-U, acetic acid modified sludge-based biochar-uranium.

that the porosity network of these materials was structured into micropores, mesopores, and macropores. According to the pore size distribution map (Figure 6A inside), SBB was mainly mesoporous and macroporous (mean pore size around $50 \mathrm{~nm}$ ), ASBB was mainly mesoporous (pores of 2 and 20-50 nm), and ASBB-U was mainly mesoporous (2 nm pores) and meso/macroporous (50 $\mathrm{nm}$ pores). By comparing the pore size distribution of ASBB before and after uranyl ion sorption, it was found that mesopores decreased after uranium sorption, indicating that the main reaction site was within this pore range. In addition, an inflection point near the monolayer sorption was observed in the isotherm. Multilayer sorption gradually took place with the increase in relative pressure. These phenomena were consistent with the fitting results by the sorption isotherm models above. 


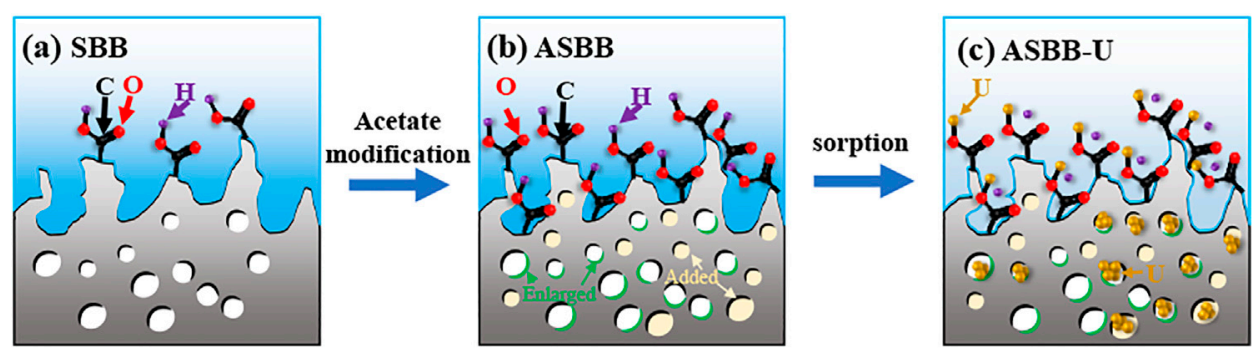

FIGURE 7 | Schematic diagram of SBB modification and uranium adsorbed by ASBB. (A) SBB, (B) ASBB, (C) ASBB-U.

The specific surface area (SSA) of ASBB increased with respect to the untreated biochar. Namely, a pore expansion function of acetic acid was observed. Then SSA for ASBB-U decreased. It indicates that uranyl ion was adsorbed in the pores of the ASBB surface. When the pores were blocked by the absorbed uranyl ion, the SSA of the adsorbent obviously decreased.

\section{Group analysis of Sludge-Based Biochar, Acetic Acid-Modified Sludge-Based biochar, and Acetic Acid-Modified Sludge-Based Biochar-Uranium}

FTIR analysis allowed to investigate the functional group modification when SBB was treated by acetic acid to give $\mathrm{ASBB}$ and the interaction of these groups with uranium during the sorption of $\mathrm{U}(\mathrm{VI})$ on ASBB. Results are illustrated in Figure 6B. According to literature (Gulnaz et al., 2005; Weng, 2010; Meng et al., 2019), $-\mathrm{OH}\left(3,427\right.$ and $\left.1,070 \mathrm{~cm}^{-1}\right),-\mathrm{COO}$ $\left(1,406\right.$ and $\left.1,617 \mathrm{~cm}^{-1}\right),-\mathrm{Si}-\mathrm{O}-\mathrm{Si} \quad\left(781 \mathrm{~cm}^{-1}\right)$, and $-\mathrm{CCl}_{4}$ $\left(476 \mathrm{~cm}^{-1}\right)$ were the main groups retrieved on the surface of SBB, ASBB, and ASBB-U. When the FTIR spectra of SBB, ASBB, and ASBB-U are compared, it is seen that -COO $\left(1,406.32 \mathrm{~cm}^{-1}\right)$ was found on the ASBB surface as a new group with respect to SBB, indicating the modification of SBB by acetic acid. Moreover, when uranium was adsorbed on ASBB, some of the peak's position and intensity changed. The peak of $-\mathrm{OH}$ stretching vibration at $1,331.37 \mathrm{~cm}^{-1}$ disappeared, indicating that $-\mathrm{OH}$ might react with $\mathrm{U}(\mathrm{VI})$ by deprotonation. In addition, the symmetric stretching vibration peak of -COO at $1,406.32 \mathrm{~cm}^{-1}$ moved to $1,384.53 \mathrm{~cm}^{-1}$. Although the peak shape was stable, its intensity was enhanced. The difference of the stretching vibration frequency between -COO antisymmetric stretching vibration peak $\left(1,617.82 \mathrm{~cm}^{-1}\right)$ and -COO symmetric stretching vibration peak $\left(1,384.53 \mathrm{~cm}^{-1}\right)$ was more than $200 \mathrm{~cm}^{-1}$ $\left(233.29 \mathrm{~cm}^{-1}\right)$. This indicates that $-\mathrm{COO}$ and $\mathrm{U}(\mathrm{VI})$ were combined in monodentate coordination mode (Weng, 2010).

Figure 6C shows the acid group content of SBB, ASBB, and ASBB-U. Compared with SBB, the contents of $-\mathrm{COOH}$ and -COO in ASBB had been increased by 0.07 and $0.04 \mathrm{mmol} / \mathrm{g}$, respectively, indicating that $\mathrm{SBB}$ had been well loaded with acetic acid, and its loading was about $0.11 \mathrm{mmol} / \mathrm{g}$. After the
$\mathrm{ASBB}$ reaction in $\mathrm{UCW}$ was completed, the content of $-\mathrm{COOH}$ was significantly reduced, while the content of $-\mathrm{COO}$ was increased, indicating the sorption of $-\mathrm{COOH}$ on $\mathrm{U}(\mathrm{VI})$. Combined with FT-IR analysis, U(VI) could be combined with -COO to purify UCW.

\section{Valence state on Acetic Acid-Modified Sludge-Based Biochar-Uranium's Surface}

Figure 6D-F present the XPS analysis results for ASBB-U's surface. From Figure 6D, it is seen that the main peak around $532 \mathrm{eV}$ belongs to $\mathrm{O} 1 \mathrm{~s}$, the peak around $285 \mathrm{eV}$ to $\mathrm{C} 1 \mathrm{~s}$, and the peak around 382 and $375 \mathrm{eV}$ to U4f. It could be concluded that the surface of ASBB-U was mainly composed of $\mathrm{C}$ and $\mathrm{O}$ elements, and a certain amount of $\mathrm{U}(\mathrm{VI})$ adsorbed on the surface. In $\mathrm{C} 1 \mathrm{~s}$ spectrum (Figure $6 \mathrm{E}$ ), the $\mathrm{C} 1 \mathrm{~s}$ component near $284.75 \mathrm{eV}$ might be associated with C-H (Ding et al., 2018). Besides, the $\mathrm{C} 1$ s spectrum could show $\mathrm{C}=\mathrm{O}$ near 285.75 and $288.86 \mathrm{eV}$ (Zhao et al., 2019). Moreover, the blending energy of $\mathrm{U}_{4} \mathrm{f}_{2 / 5}(382.4 \mathrm{eV}, 385.2 \mathrm{eV})$ corresponded to $\mathrm{U}(\mathrm{VI})$ on the surface of ASBB-U (Figure 6F) (Husnain et al., 2017; Tan et al., 2018), indicating that no redox reaction happened in uranium sorption process by ASSB.

\section{Mechanism of Modification and Sorption}

Following the experimental results, various characterization methods (BET, SEM, EDS, FTIR, XPS), and relevant references (Li et al., 2021; Liu et al., 2021), the mechanism of SBB modification and uranium sorption by ASBB was inferred. A schematic diagram is displayed in Figure 7: 1) The reaction probability of ASBB to uranium was greatly improved, due to the increased pore diameter, specific surface area, and functional group (-COOH) number by acetic acid modification of SBB. 2) The most suitable interaction between uranium ion and adsorbent under suitable reaction conditions might be of van der Waals type (Hussein et al., 2016), as witnessed by the decrease in SSA and pore size after the reaction of ASBB with USW. 3) $-\mathrm{COOH}$ had a good uranium sorption behavior (Park et al., 2019). At $\mathrm{pH}=5,-\mathrm{H}$ on $-\mathrm{COOH}$ could be easily replaced by uranium, which mainly existed in the form of $\left(\mathrm{UO}_{2}\right)_{3}(\mathrm{OH})_{5}{ }^{+}$and $\left(\mathrm{UO}_{2}\right)_{4}(\mathrm{OH})_{7}{ }^{+}$. They were combined with -COO in monodentate coordination. The specific equation reads (Eq. 7): 
<smiles>O=C(O)C(=O)O[18OH]</smiles>

\section{CONCLUSION}

Excess sludge (ES) and acetic acid were utilized to obtain a robust adsorbent starting from sludge-based biochar (SBB), for U(VI) abatement in uranium-containing wastewater (UCW). Compared with SBB, the removal efficiency and sorption capacity of the acetic acid-modified biochar (ASBB) could be effectively improved. An optimal U(VI) removal rate of 97.8\% could be achieved, while initial conditions were $\mathrm{pH}=6.0, \mathrm{U}(\mathrm{VI})=10.0 \mathrm{mg} / \mathrm{L}$ (initial concentration), adsorbent dosage $=0.30 \mathrm{~g} / \mathrm{L}$, and sorption time $=5.0 \mathrm{~min}$. The beneficial effect was attributed to the double action of expanding pores and increasing $-\mathrm{COOH}$ functional groups following the acetic acid modification treatment. The process of $\mathrm{U}(\mathrm{VI})$ sorption by modified biochar relies on both physical and chemical sorption. The U(VI) removal mechanism by ASBB was of monodentate coordination binding between - $\mathrm{COO}-$ and uranium. In addition, ASBB had good reusable performance. Hence, the quick sorption and outstanding efficiency of ASBB offer a meaningful support for the use of biochar in uranium recovery from UCW and for reutilization of ES.

\section{REFERENCES}

Abadi, S. R. H., Sebzari, M. R., Hemati, M., Rekabdar, F., and Mohammadi, T. (2011). Ceramic Membrane Performance in Microfiltration of Oily Wastewater [J]. Desalination 265 (1-3), 222-228. doi:10.1016/j.desal.2010.07.055

Abdi, S., Nasiri, M., Mesbahi, A., and Khani, M. H. (2017). Investigation of Uranium (VI) Adsorption by Polypyrrole. J. Hazard. Mater. 332, 132-139. doi:10.1016/j.jhazmat.2017.01.013

Alatalo, S. M., Repo, E., Mäkilä, E., Salonen, J., Vakkilainen, E., and Sillanpää, M. (2013). Adsorption Behavior of Hydrothermally Treated Municipal Sludge \& Pulp and Paper Industry Sludge. Bioresour. Technol. 147, 71-76. doi:10.1016/j. biortech.2013.08.034

Ali, Z., Chen, Z., Wang, X., and Zhang, Q. (2019). Microwave-assisted Pyrolysis of Sewage Sludge: A Review[J]. Fuel Process. Technol. 187, 84-104.

Anirudhan, T. S., and Deepa, J. R.Binusreejayan (2015). Synthesis and Characterization of Multi-Carboxyl-Functionalized Nanocellulose/ nanobentonite Composite for the Adsorption of Uranium(VI) from Aqueous Solutions: Kinetic and Equilibrium Profiles. Chem. Eng. J. 273, 390-400. doi:10.1016/j.cej.2015.03.007

Anirudhan, T. S., Lekshmi, G. S., and Shainy, F. (2019). Synthesis and Characterization of Amidoxime Modified Chitosan/bentonite Composite for the Adsorptive Removal and Recovery of Uranium from Seawater. J. Colloid Interf. Sci. 534, 248-261. doi:10.1016/j.jcis.2018. 09.009

Anna, C.-P., Justyna, S.-B., and Wojciech, L. (2018). Optimization of Copper, lead and Cadmium Biosorption onto Newly Isolated Bacterium Using a BoxBehnken Design[J]. Ecotoxicology Environ. Saf. 149, 275-283.

Baur, X., Rihs, H.-P., Altmeyer, P., Degens, P., Conrad, K., Mehlhorn, J., et al. (1996). Systemic Sclerosis in German Uranium Miners under Special Consideration of Autoantibody Subsets and Hla Class Ii Alleles. Respiration 63 (6), 368-375. doi:10.1159/000196579

Bruno, J., De Pablo, J., Duro, L., and Figuerola, E. (1995). Experimental Study and Modeling of the $\mathrm{U}(\mathrm{VI})-\mathrm{Fe}(\mathrm{OH}) 3$ Surface Precipitation/coprecipitation Equilibria. Geochimica et Cosmochimica Acta 59 (20), 4113-4123. doi:10. 1016/0016-7037(95)00243-s

\section{DATA AVAILABILITY STATEMENT}

The original contributions presented in the study are included in the article/Supplementary Material, further inquiries can be directed to the corresponding author.

\section{AUTHOR CONTRIBUTIONS}

SY: Resources, Investigation, Writing-Original Draft. XW: Validation, Writing-Review and Editing. JY: Validation. ML: Validation, Visualization. QZ: Investigation. XZ: Validation. CL: Investigation. WX: Investigation. KS: Investigation. YL: Supervision.

\section{FUNDING}

This study was financially supported by the National Natural Science Fund of China (Nos. 51704169, 51874180, 11875164), National Defense Science and Technology Bureau of China on the "13th Five-Year Plan" Technology Basic Scientific Research Project (No. JSZL2018 ${ }^{\star * * *} 001$, JSZL2018 ${ }^{\star * * \star} 008$ ), Hunan Provincial Innovation Foundation for Postgraduate (No. CX20190711), and Research and Development Projects in Key Areas of Hunan Province (No. 2019SK 2011).

Cai, H., Lin, X., Qin, Y., and Luo, X. (2017). Hydrothermal Synthesis of Carbon Microsphere from Glucose at Low Temperature and its Adsorption Property of Uranium(VI). J. Radioanal. Nucl. Chem. 311 (1), 695-706. doi:10.1007/s10967016-5106-9

Chen, T., Zhang, J., Ge, H., Li, M., Li, Y., liu, B., et al. (2020). Efficient Extraction of Uranium in Organics-Containing Wastewater over G-C3n4/GO Hybrid Nanosheets with Type-II Band Structure. J. Hazard. Mater. 384, 121383. doi:10.1016/j.jhazmat.2019.121383

Christou, C., Philippou, K., Krasia-Christoforou, T., and Pashalidis, I. (2019). Uranium Adsorption by Polyvinylpyrrolidone/chitosan Blended Nanofibers. Carbohydr. Polym. 219, 298-305. doi:10.1016/j. carbpol.2019.05.041

Deb, A. K. S., Ilaiyaraja, P., Ponraju, D., and Venkatraman, B. (2012). Diglycolamide Functionalized Multi-Walled Carbon Nanotubes for Removal of Uranium from Aqueous Solution by Adsorption[J]. J. Radioanal. Nucl. Chem. 291 (3), 877-883.

Ding, L., Tan, W.-F., Xie, S.-B., Mumford, K., Lv, J.-W., Wang, H.-Q., et al. (2018). Uranium Adsorption and Subsequent Re-oxidation under Aerobic Conditions by Leifsonia Sp. - Coated Biochar as green Trapping Agent. Environ. Pollut. 242, 778-787. doi:10.1016/j.envpol.2018.07.050

Ebrahim, Y. S. M., Salem Nafisa, A., and Abdeltawab Ahmed, A. (2017). Equilibrium and Thermodynamics for Adsorption of Uranium onto Potassium Hydroxide Oxidized Carbon[J]. Desalination Water Treat. 72, 335-342.

El-MagiedAbd, M. O. A., Mohammaden, T. F., El-Aassy, I. K., Gad, H. M. H., Hassan, A. M., and Mahmoud, M. A. (2017). Decontamination of UraniumPolluted Groundwater by Chemically-Enhanced, Sawdust-Activated Carbon. Colloids Inter. 1 (1), 2. doi:10.3390/colloids1010002

Fang-Zhu, X., Cheng, W., Li-Mei, Y., Yi-Qiu, P., Yu-Li, X., Kang, Z., et al. (2019). Fabrication of Magnetic Functionalised Calix 4 Arene Composite for Highly Efficient and Selective Adsorption towards Uranium(VI)[J]. Environ. Chem. 16 (8), 577-586.

Feng, Q., Zhang, Z., Chen, Y., Liu, L., Zhang, Z., and Chen, C. (2013). Adsorption and Desorption Characteristics of Arsenic on Soils: Kinetics, Equilibrium, and Effect of $\mathrm{Fe}(\mathrm{OH}) 3$ Colloid, H2SiO3 Colloid and Phosphate. Proced. Environ. Sci. 18, 26-36. doi:10.1016/j.proenv.2013.04.005 
Gerber, U., Zirnstein, I., Krawczyk-Bärsch, E., Lünsdorf, H., Arnold, T., and Merroun, M. L. (2016). Combined Use of Flow Cytometry and Microscopy to Study the Interactions between the Gram-Negative Betaproteobacterium Acidovorax Facilis and Uranium(VI). J. Hazard. Mater. 317, 127-134. doi:10. 1016/j.jhazmat.2016.05.062

Ghosh, P. (2009). Biological Treatment Processes[J]. Handbook Environ. Eng. 80 (2), 69-72.

Guanhai, M., Qing, H., Guohua, W., Shuibo, X., Haidu, N., Xiaoling, Z., et al. (2021). $\mathrm{Fe}_{3} \mathrm{O}_{4}$-modified Sewage Sludge Biochar for U(VI) Removal from Aqueous Solution: Performance and Mechanism[J]. J. Radioanal. Nucl. Chem. 329 (1), 225-237.

Gulnaz, O., Saygideger, S., and Kusvuran, E. (2005). Study of Cu(II) Biosorption by Dried Activated Sludge: Effect of Physico-Chemical Environment and Kinetics Study. J. Hazard. Mater. 120 (1-3), 193-200. doi:10.1016/j.jhazmat.2005.01.003

Hossain, M. I., Paparini, A., and Cord-Ruwisch, R. (2018). Direct Oxygen Uptake from Air by Novel Glycogen Accumulating Organism Dominated Biofilm Minimizes Excess Sludge Production. Sci. Total Environ. 640-641, 80-88. doi:10.1016/j.scitotenv.2018.05.292

Hu, W., Xie, Y., Lu, S., Li, P., Xie, T., Zhang, Y., et al. (2019). One-step Synthesis of Nitrogen-Doped Sludge Carbon as a Bifunctional Material for the Adsorption and Catalytic Oxidation of Organic Pollutants. Sci. Total Environ. 680, 51-60. doi:10.1016/j.scitotenv.2019.05.098

Husnain, S. M., KimJu, H. J., Um, W., Chang, Y.-Y., and Chang, Y.-S. (2017). Superparamagnetic Adsorbent Based on Phosphonate Grafted Mesoporous Carbon for Uranium Removal. Ind. Eng. Chem. Res. 56 (35), 9821-9830. doi:10. 1021/acs.iecr.7b01737

Hussein, A., Fares Mohammad, M., and Abu Al-Rub Fahmi, A. (2016). Removal of Uranium and Associated Contaminants from Aqueous Solutions Using Functional Carbon Nanotubes-Sodium Alginate Conjugates[J]. Minerals 6 (1), 9 .

Ioanna, L., Georgia, M., Marilena, D., and Ioannis, P. (2017). Uranium Binding by Biochar Fibres Derived from Luffa Cylindrica after Controlled Surface Oxidation[J]. J. Radioanal. Nucl. Chem. 311 (1), 871-875.

Ismail Cem, K., and Jale, Y. (2009). Use of Waste Sludge from the Tannery Industry [J]. Energy \& Fuels 23 (6), 3126-3133.

Jiang, X., Wang, H., Wang, Q., Hu, E., and Duan, Y. (2020). Immobilizing AminoFunctionalized Mesoporous Silica into Sodium Alginate for Efficiently Removing Low Concentrations of Uranium. J. Clean. Prod. 247, 119162. doi:10.1016/j.jclepro.2019.119162

Jin, J., Li, S., Peng, X., Liu, W., Zhang, C., Yang, Y., et al. (2018). HNO3 Modified Biochars for Uranium (VI) Removal from Aqueous Solution. Bioresour. Technol. 256, 247-253. doi:10.1016/j.biortech.2018.02.022

Kalijadis, A., Vukcevic, M., Jovanovic, Z., Lausevic, Z., and Lausevic, M. (2011). Characterization of Surface Oxygen Groups on Different Carbon Materials by the Boehm Method and Temperature Programmed Desorption. J. Serbian Chem. Soc. 76 (5), 757-768. doi:10.2298/jsc091224056k

Kataria, N., and Garg, V. K. (2018). Green Synthesis of Fe3O4 Nanoparticles Loaded Sawdust Carbon for Cadmium (II) Removal from Water: Regeneration and Mechanism. Chemosphere 208, 818-828. doi:10.1016/j.chemosphere.2018. 06.022

Kathren, R. L., and Burklin, R. K. (2008). Acute Chemical Toxicity of Uranium. Health Phys. 94 (2), 170-179. doi:10.1097/01.hp.0000288043.94908.1f

Khani, M. H., Keshtkar, A. R., Ghannadi, M., and Pahlavanzadeh, H. (2008). Equilibrium, Kinetic and Thermodynamic Study of the Biosorption of Uranium onto Cystoseria Indica Algae. J. Hazard. Mater. 150 (3), 612-618. doi:10.1016/j. jhazmat.2007.05.010

Khawassek, Y. M., Masoud, A. M., Taha, M. H., and Hussein, A. E. M. (2018). Kinetics and Thermodynamics of Uranium Ion Adsorption from Waste Solution Using Amberjet $1200 \mathrm{H}$ as Cation Exchanger. J. Radioanal. Nucl. Chem. 315 (3), 493-502. doi:10.1007/s10967-017-5692-1

Kong, L., Ruan, Y., Zheng, Q., Su, M., Diao, Z., Chen, D., et al. (2020). Uranium Extraction Using Hydroxyapatite Recovered from Phosphorus Containing Wastewater. J. Hazard. Mater. 382, 120784. doi:10.1016/j.jhazmat.2019.120784

Li, F., Meng, F., Wang, H., Ge, B., Zhang, Y., and Yu, C. (2019). Urea-modified Grass Ash Activated Sludge Carbon: Structure and Adsorption Properties towards H2S and CH3SH. New J. Chem. 43 (44), 17494-17501. doi:10.1039/ c9nj03836a
Li, H., Li, Y., Li, B., Dai, Y., and Chen, X. (2020). Melamine-induced Novel MSONs Heterostructured Framework: Controlled-Switching between MOF and SOF via a Self-Assembling Approach for Rapid Uranium Sequestration. Chem. Eng. J. 379, 122279. doi:10.1016/j.cej.2019.122279

Li, M., Liu, H., Chen, T., Dong, C., and Sun, Y. (2019). Synthesis of Magnetic Biochar Composites for Enhanced Uranium(VI) Adsorption. Sci. Total Environ. 651, 1020-1028. doi:10.1016/j.scitotenv.2018.09.259

Li, M., Liu, Y., Li, F., Shen, C., Kaneti, Y. C., Yamauchi, Y., et al. (2021). Defect-Rich Hierarchical Porous UiO-66(Zr) for Tunable Phosphate Removal[J]. Environ. Sci. Technol. 55 (19), 13209-13218.

Li, P., Wang, J., Wang, X., He, B., Pan, D., Liang, J., et al. (2018). Arsenazo-functionalized Magnetic Carbon Composite for Uranium(VI) Removal from Aqueous Solution. J. Mol. Liquids 269, 441-449. doi:10.1016/j.molliq.2018.08.073

Liu, F., You, S., Wang, Z., and Liu, Y. (2021). Redox-Active Nanohybrid Filter for Selective Recovery of Gold from Water. ACS EST Eng. 1 (9), 1342-1350. doi:10. 1021/acsestengg.1c00158

Liu, H., Xie, S., Liao, J., Yan, T., Liu, Y., and Tang, X. (2018). Novel Graphene Oxide/ bentonite Composite for Uranium(VI) Adsorption from Aqueous Solution. J. Radioanal. Nucl. Chem. 317 (3), 1349-1360. doi:10.1007/s10967-018-5992-0

Lu, B.-q., Li, M., Zhang, X.-w., Huang, C.-m., Wu, X.-y., and Fang, Q. (2018). Immobilization of Uranium into Magnetite from Aqueous Solution by Electrodepositing Approach. J. Hazard. Mater. 343, 255-265. doi:10.1016/j. jhazmat.2017.09.037

Lu, S., Liu, Y., Feng, L., Sun, Z., and Zhang, L. (2018). Characterization of Ferromagnetic Sludge-Based Activated Carbon and its Application in Catalytic Ozonation of P-Chlorobenzoic Acid. Environ. Sci. Pollut. Res. 25 (6), 5086-5094. doi:10.1007/s11356-017-8680-7

Malenchenko, A. F., Barkun, N. A., and Guseva, G. F. (1978). Effect of Uranium on the Induction and Course of Experimental Autoimmune Orchitis and Thyroiditis. J. Hyg. Epidemiol. Microbiol. Immunol. 22 (3), 268-277.

Meng, F., Gong, Z., Wang, Z., Fang, P., and Li, X. (2019). Study on a NitrogenDoped Porous Carbon from Oil Sludge for CO2 Adsorption. Fuel 251, 562-571. doi:10.1016/j.fuel.2019.04.046

Mishra, V., Sureshkumar, M. K., Gupta, N., and Kaushik, C. P. (2017). Study on Sorption Characteristics of Uranium onto Biochar Derived from Eucalyptus Wood. Water Air Soil Pollut. 228 (8), 309. doi:10.1007/s11270-017-3480-8

Morsy, A. M. A., and Hussein, A. E. M. (2011). Adsorption of Uranium from Crude Phosphoric Acid Using Activated Carbon. J. Radioanal. Nucl. Chem. 288 (2), 341-346. doi:10.1007/s10967-011-0980-7

NaserHumood, H. A. (2013). Assessment and Management of Heavy Metal Pollution in the marine Environment of the Arabian Gulf: A Review. Mar. Pollut. Bull. 72 (1), 6-13. doi:10.1016/j.marpolbul.2013.04.030

Park, J., Bae, J., Jin, K., and Park, J. (2019). Carboxylate-functionalized Organic Nanocrystals for High-Capacity Uranium Sorbents. J. Hazard. Mater. 371, 243-252. doi:10.1016/j.jhazmat.2019.03.007

Pu, D., Kou, Y., Zhang, L., Liu, B., Zhu, W., Zhu, L., et al. (2019). Waste Cigarette Filters: Activated Carbon as a Novel Sorbent for Uranium Removal. J. Radioanal. Nucl. Chem. 320 (3), 725-731. doi:10.1007/s10967-019-06502-z

Saleh, T. A., Naeemullah, T. M., Tuzen, M., and Sarı, A. (2017). Polyethylenimine Modified Activated Carbon as Novel Magnetic Adsorbent for the Removal of Uranium from Aqueous Solution. Chem. Eng. Res. Des. 117, 218-227. doi:10. 1016/j.cherd.2016.10.030

Schierz, A., and Zänker, H. (2009). Aqueous Suspensions of Carbon Nanotubes: Surface Oxidation, Colloidal Stability and Uranium Sorption. Environ. Pollut. 157 (4), 1088-1094. doi:10.1016/j.envpol.2008.09.045

Sun, S., Zhang, S., Zhang, W., Meng, J., and Wang, L. (2018). Reduction and Heavy Metals Removal of Excess Sludge by Radio Frequency Discharge Plasma. IOP Conf. Ser. Earth Environ. Sci. 146, 012069. doi:10.1088/1755-1315/146/1/012069

Sun, Y., Shao, D., Chen, C., Yang, S., and Wang, X. (2013). Highly Efficient Enrichment of Radionuclides on Graphene Oxide-Supported Polyaniline. Environ. Sci. Technol. 47 (17), 9904-9910. doi:10.1021/es401174n

Sun, Y., Wang, X., Ai, Y., Yu, Z., Huang, W., Chen, C., et al. (2017). Interaction of Sulfonated Graphene Oxide with U(VI) Studied by Spectroscopic Analysis and Theoretical Calculations. Chem. Eng. J. 310, 292-299. doi:10.1016/j.cej.2016. 10.122

Tan, Y., Li, L., Zhang, H., Ding, D., Dai, Z., Xue, J., et al. (2018). Adsorption and Recovery of U(VI) from Actual Acid Radioactive Wastewater with Low Uranium Concentration Using Thioacetamide Modified Activated Carbon 
from Liquorice Residue. J. Radioanal. Nucl. Chem. 317 (2), 811-824. doi:10. 1007/s10967-018-5952-8

Tu, H., Lan, T., Yuan, G., Zhao, C., Liu, J., Li, F., et al. (2019). The Influence of Humic Substances on Uranium Biomineralization Induced by Bacillus Sp. Dwc-2. J. Environ. Radioactivity 197, 23-29. doi:10.1016/j.jenvrad.2018. 11.010

Wang, G., Liu, J., Wang, X., Xie, Z., and Deng, N. (2009). Adsorption of Uranium (VI) from Aqueous Solution onto Cross-Linked Chitosan. J. Hazard. Mater. 168 (2-3), 1053-1058. doi:10.1016/j.jhazmat.2009.02.157

Wen, T., Wang, X., Wang, J., Chen, Z., Li, J., Hu, J., et al. (2016). A Strategically Designed Porous Magnetic N-Doped Fe/Fe3C@C Matrix and its Highly Efficient Uranium(vi) Remediation. Inorg. Chem. Front. 3 (10), 1227-1235. doi:10.1039/c6qi00091f

Weng, Pushi. (2010). Fourier Transform Infrared Spectrum analysis[M]. Beijing, China: Chemical Industrial Press.

Wu, F., Pu, N., Ye, G., Sun, T., Wang, Z., Song, Y., et al. (2017). Performance and Mechanism of Uranium Adsorption from Seawater to Poly(dopamine)Inspired Sorbents. Environ. Sci. Technol. 51 (8), 4606-4614. doi:10.1021/acs. est.7b00470

Wu, J., Tian, K., and Wang, J. (2018). Adsorption of Uranium (VI) by Amidoxime Modified Multiwalled Carbon Nanotubes. Prog. Nucl. Energ. 106, 79-86. doi:10. 1016/j.pnucene.2018.02.020

Wu, Y., Chen, D., Kong, L., Tsang, D. C. W., and Su, M. (2019). Rapid and Effective Removal of Uranium (VI) from Aqueous Solution by Facile Synthesized Hierarchical Hollow Hydroxyapatite Microspheres. J. Hazard. Mater. 371, 397-405. doi:10.1016/j.jhazmat.2019.02.110

Xiong, J., Hu, S., Liu, Y., Yu, J., Yu, H., Xie, L., et al. (2017). Polypropylene Modified with Amidoxime/Carboxyl Groups in Separating Uranium(VI) from Thorium(IV) in Aqueous Solutions. ACS Sustain. Chem. Eng. 5 (2), 1924-1930. doi:10.1021/acssuschemeng.6b02663

Zeng, T., Mo, G., Zhang, X., Liu, J., Liu, H., and Xie, S. (2020). U(VI) Removal Efficiency and Mechanism of Biochars Derived from Sewage Sludge at Two Pyrolysis Temperatures. J. Radioanal. Nucl. Chem. 326 (2), 1413-1425. doi:10. 1007/s10967-020-07423-y

Zhao, C., Liu, J., Deng, Y., Tian, Y., Zhang, G., Liao, J., et al. (2019). Uranium(VI) Adsorption from Aqueous Solutions by Microorganism-Graphene Oxide Composites via an Immobilization Approach. J. Clean. Prod. 236, 117624. doi:10. 1016/j.jclepro.2019.117624

Zhao, W., Lin, X., Qin, Y., Cai, H., Chen, Y., and Luo, X. (2017). Preparation of Chemically Oxidized Porous Carbon and its Adsorption of Uranium(VI) from
Aqueous Solution. J. Radioanal. Nucl. Chem. 314 (3), 1853-1864. doi:10.1007/s10967017-5559-5

Zhao, Z., Li, J., Wen, T., Shen, C., Wang, X., and Xu, A. (2015). Surface Functionalization Graphene Oxide by Polydopamine for High Affinity of Radionuclides. Colloids Surf. A: Physicochemical Eng. Aspects 482, 258-266. doi:10.1016/j.colsurfa.2015.05.020

Zhu, J., Liu, Q., Li, Z., Liu, J., Zhang, H., Li, R., et al. (2018). Efficient Extraction of Uranium from Aqueous Solution Using an Amino-Functionalized Magnetic Titanate Nanotubes. J. Hazard. Mater. 353, 9-17. doi:10.1016/j.jhazmat.2018.03.042

Zhuang, S., Cheng, R., Kang, M., and Wang, J. (2018). Kinetic and Equilibrium of $\mathrm{U}(\mathrm{VI})$ Adsorption onto Magnetic AmidoximeFunctionalized Chitosan Beads. J. Clean. Prod. 188, 655-661. doi:10. 1016/j.jclepro.2018.04.047

Zong, P., Cao, D., Cheng, Y., Zhang, H., Shao, D., Wang, S., et al. (2017). Functionally Reduced Graphene Oxide Supported Iron Oxides Composites as an Adsorbent for the Immobilization of Uranium Ions from Aqueous Solutions. J. Mol. Liquids 240, 578-588. doi:10.1016/j. molliq.2017.05.101

Zong, P., Wu, X., Gou, J., Lei, X., Liu, D., and Deng, H. (2015). Immobilization and Recovery of Uranium(VI) Using Na-Bentonite from Aqueous Medium: Equilibrium, Kinetics and Thermodynamics Studies. J. Mol. Liquids 209, 358-366. doi:10.1016/j.molliq.2015.05.052

Conflict of Interest: The authors declare that the research was conducted in the absence of any commercial or financial relationships that could be construed as a potential conflict of interest.

Publisher's Note: All claims expressed in this article are solely those of the authors and do not necessarily represent those of their affiliated organizations, or those of the publisher, the editors, and the reviewers. Any product that may be evaluated in this article, or claim that may be made by its manufacturer, is not guaranteed nor endorsed by the publisher.

Copyright $\odot 2022 \mathrm{Yu}, \mathrm{Wu}, \mathrm{Ye}$, Li, Zhang, Zhang, Lv, Xie, Shi and Liu. This is an open-access article distributed under the terms of the Creative Commons Attribution License (CC BY). The use, distribution or reproduction in other forums is permitted, provided the original author(s) and the copyright owner(s) are credited and that the original publication in this journal is cited, in accordance with accepted academic practice. No use, distribution or reproduction is permitted which does not comply with these terms. 